\title{
Monitoring of the Corrosion of Pipes Used for the Drinking Water Treatment and Supply
}

\author{
Kateřina Slavíčková ${ }^{*}$ Alexander Grünwald, Bohumil Št’astný \\ Czech Technical University in Prague, Faculty of Civil Engineering, Dept. of Sanitary and Ecological Engineering, Thákurova 7, 16629 \\ Praha 6, Czech Republic \\ *Corresponding Author: katerina.slavickova@fsv.cvut.cz
}

Copyright (C) 2013 Horizon Research Publishing All rights reserved.

\begin{abstract}
The corrosion of steel pipes used for drinking water supply can be a cause of failure of pipes and problems with quality of drinking water. The research presented in this paper focuses on corrosion rates measurement using removable steel coupons. From pre-tests carried out, it was decided to use two exposure periods: 35 and 70 days. After these periods the coupons were removed, loss of weight of the coupon was evaluated and coupons were analysed by the new Matlab method which can determine corrosion coupon areas affected by uniform and pitting corrosion. Corrosion rates were computed for corroded areas of the coupon. Corrosion measurement and evaluation can help to decrease the deterioration of drinking water quality for consumers.
\end{abstract}

Keywords Corrosion, Coupon tests, Drinking Water

\section{Introduction}

Internal corrosion of water distribution systems gives rise to many problems for water utilities. The first is the failure of the distribution system pipes which often results in water leakage. The problem is also loss of hydraulic capacity caused by build-up of corrosion products. The next one is an unwanted change in the water quality caused by corrosion products entering the water. Corrosion monitoring using the coupon tests can help to optimize drinking water quality parameters and it also can help to plan reconstructions of pipes used for drinking water delivery. Corrosion negatively influences the quality of distributed water in many parameters. For example colour, turbidity, conductivity and iron concentration increase and content of dissolved oxygen and active chlorine decrease. In cast iron and steel pipe, the major corrosion problems are associated with the build-up of corrosion products on the pipe walls and the release of corrosion products into the water. The most common indicators of corrosion in the distribution system are red water complaints and leaks. Corrosion of iron is also the primary factor controlling biofilm growth.

The solution of drinking water corrosion problems requires the careful review of finished water characteristics, materials in the distribution system and their protection against corrosion, types and locations of complaints, and review of water quality in the distribution system - in all areas. In the past decades, numerous studies have been conducted to investigate iron corrosion to elucidate fundamental mechanisms responsible for iron release, which often causes red water. It is known, that corrosion processes consist of a series of electrochemical reaction occurring at the metal surface in contact with water and its constituents.

Corrosiveness of particular water depends on its chemical properties (e.g. pH, alkalinity, dissolved oxygen content, dissolved solids etc) and physical characteristics (temperature, flow, velocity), as well as the nature of the pipe material. In addition to general corrosion, localized pitting corrosion may also occur if there are imperfections in the metal, oxide film or scale. Pitting is accelerated by high levels of chloride and sulfate. Microorganisms can also promote corrosion by creating areas with different concentrations in oxygen, minerals and metals. Some microorganisms also catalyze reactions associated with corrosion process. Corrosion products of iron pipe provide habitats for microbial growth and react with disinfectant residuals, preventing the disinfectant from penetrating the biofilm [1]. Corrosion scales formed by the accumulation of corrosion products could serve as the breeding ground for microbes and sinks for heavy metals or other contaminants (e.g., arsenic, vanadium, lead) $[2,3]$.

The term corrosion covers both types of corrosion pitting and uniform corrosion. Pitting corrosion is represented by small pits formed in the surface of the steel. Dependent upon both the environment and the steel itself these small pits may continue to grow, and if they do that it can lead to perforation, while the majority of the steel surface may still be totally unaffected. Uniform corrosion is the attack of a metal at essentially the same at all exposed areas of its surface. At no point is the penetration of the metal by corrosion twice as great as the average rate. [4]

What sets uniform corrosion apart is that it proceeds at about the same rate over the whole surface of the metal exposed to the corrosive environment. The extent can be 
given as a mass loss per unit area or by the average penetration, which is the average of the corrosion depth. This can be determined by direct measurement or by calculation from the mass loss per unit area, when the density of the material is known.

Corrosion rates are commonly computed for the whole area of a corrosion coupon used for coupon tests. The new approach of this study is in the fact, that corrosion coupons are evaluated in Matlab and corrosion rates are computed for the corroded part of the coupon.

\section{Materials and Methods}

Monitoring and corrosion measurement is an important part of monitoring of stages of the drinking water supply system and its changes. It can be used for determining the efficiency of arrangements against corrosion during a chemical water treatment.

\subsection{Corrosion Measurement}

The measurement of corrosion during water treatment and distribution helps to deduce the optimal conditions for water treatment $(\mathrm{pH}$, temperature, alkalinity), which limit or stop the corrosion. Measurements results are used to extend the working life of facilities, improve water quality, predict method and time of maintenance and in its result they help to decrease operational costs. Some techniques give results immediately, other inform us about corrosion rates or about the total corrosion.

Monitoring techniques can be divided into three basic groups:

Metal decay measurements - a physical decay of material caused by the corrosion or an erosion,

Electrochemical measurements - corrosion effects of the environment are measured without viewing the actual decay of a material,

Subsidiary analyses - total iron, biological film, $\mathrm{pH}$ etc.; laboratory experiments which help to understand the system.

Common Corrosion Index Calculations are used in the industry. Corrosion indices are many and have been used historically for an evaluation of corrosion. However, for drinking water, finding a way to accurately calculate corrosion has not been able to be simplified into numerical equations. The indices include for example Langelier Saturation Index (LSI) or Ryznar Stability Index (RSI). The limitation of these indices is based on the fact that so many factors contribute to corrosion in a particular situation in the distribution system. A given corrosive environment can be a result of such factors as dissolved oxygen, $\mathrm{pH}$, alkalinity, hardness, suspended solids, organic matter, ammonia, specific anions (phosphate, nitrite, sulfate, and chloride), biological slimes, and temperature. [5]

\subsection{Coupon Tests}

A corrosion coupon test belongs to metal decay measurements techniques. It is a widely used and relatively simple method for the corrosion monitoring. It is based on the accurate measurement of the decrease of weight of iron of exposed samples. The time of exposure is usually 30,60 or 90 days. The exact technique of coupon tests used in Czech Republic is written in TNV 757121 directive „Requirements on water quality distributed by a pipe network " The tests are carried out with testing coupons made from a steel plate of class 11, thickness $1 \mathrm{~mm}$ with a surface without corrosion with size of $42 \times 42 \mathrm{~mm}$. Each coupon is marked with a number by a punch; they are mechanically cleaned and then cleaned with an organic degreased agent. It is also cleaned from potential corrosion products by a short staining in solution of hydrochloric acid with hexamethylenetetramine. It is washed with distilled water and after with ethanol, dried by hot air and then it is placed to desiccator. After that each coupon is weighed with an accuracy of $0,0005 \mathrm{~g}$ and they are fasten to special holders five pieces to each holder. Four of them are these steel coupons and one is made from glass. Glass coupons are used to evaluate biofilm density.

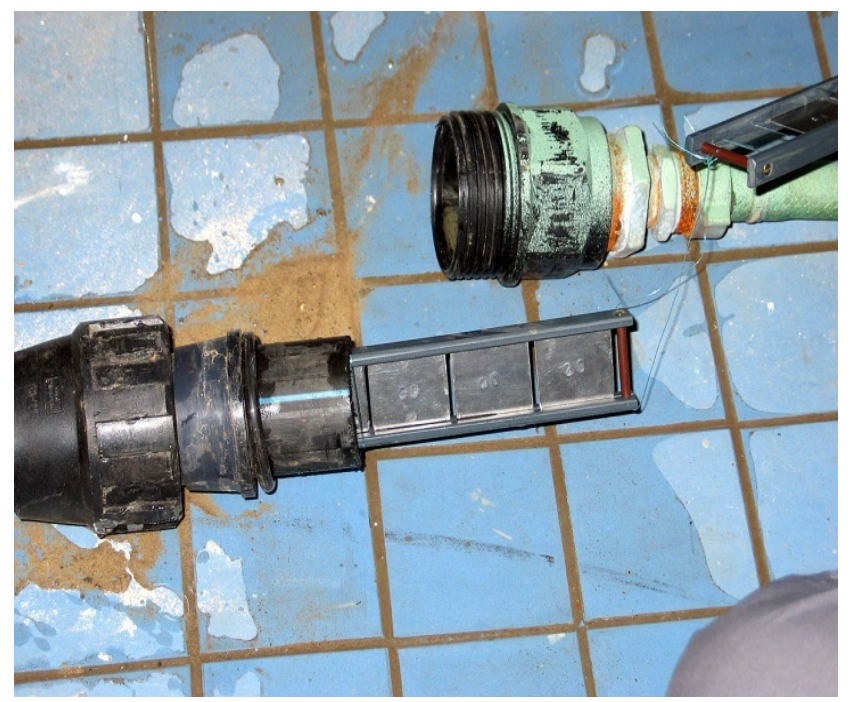

Figure 1. Holder with steel coupons

Holder with coupons is inserted into vertically placed pipe (Figure 1) connected to inlet and outlet water pipeline. Flow, temperature and active chlorine concentration are measured and recorded during the test. The coupons are removed from the cradles after incubation period which varies from a 30 to 90 days. For the experiments discussed in this paper 35 and 70 days periods were used on the base of pre-tests carried out. At the end of the test steel coupons are stained again in hydrochloric acid solution to remove all the corrosion products. They are washed with distilled water, ethanol and dried by hot air and then they are placed to desiccator. Each coupon is weighted after getting cold.

\subsection{Corrosion Evaluation}

2.2. 1. Corrosion Coupons Evaluation 
The standard method of coupon tests evaluation use the loss of weight of the coupon for computation of the decay of the material on the whole area of the coupon. The computed corrosion rate refers to the whole area of the coupon. This method is widely used.

\subsubsection{Corrosion Coupons Evaluation using Scanner Method and Matlab Software}

This new method can give more accurate results for coupons where the corrosion is not distributed equally.

A scanner method was used to transform the cleaned metal coupons used for coupon tests to their picture in electronic form necessary for Matlab evaluation. Each coupon was scanned from both sides and two pictures were done.

Matlab software was used to define the new method of corrosion rate calculation and differentiation between two types of corrosion: uniform and pitting corrosion.

Corrosion of coupons covers both types of corrosion pitting and uniform and it is expressed in units $\mathrm{m}^{2}$ or in percentages from the total area of the coupon. It was necessary to define the percentage of corroded area from the whole area of the corrosion coupon. Both types of corrosion - uniform and pitting - were separately recognized and defined in percentage of the whole area of the coupon for each coupon in Matlab software. After that process it was possible to use this data for more accurate corrosion rate computation.

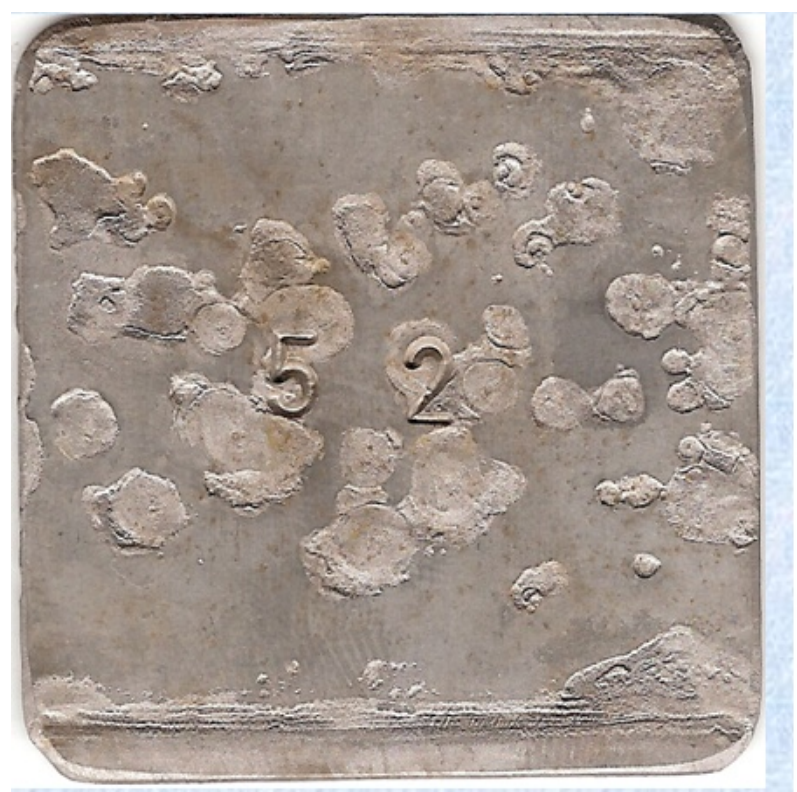

Matlab software was used for this differentiation and evaluation for these reasons: it is possible to create algorithms in it; it can model a big amount of data and integrate mathematical computations and visualizations. That's why it can quickly, simply and effectively specify required parameters.

As the first task it was necessary to create an algorithm which can distinguish corroded and not corroded area from the scanned picture of the corrosion coupon. It should also distinguish pitting and uniform corrosion. Each side of the coupon was evaluated separately. The first step was a transfer of the picture to black and white colors. Number 0 was associated to white color which represents the corroded area and number 1 was associated to black color which represents the not corroded area (Figure 2).

The percentage of the corroded area is determined by the sum of points with 0 values. It covers uniform and pitting corrosion. An algorithm for pitting corrosion computation was created on the base of two different circles which were used for small white points searching in matrix 40x40 pixels. This approach was repeated till the whole picture was analyzed. These points were visualized with red colour (Figure 3) and their summarization represents pitting corrosion. The uniform corrosion area was computed by subtraction of pitting corrosion area from the total corroded area. It was expressed in percentage of corroded area. [6]

Figure 2. Evaluation of the corrosion with the help of scanner method and Matlab software 


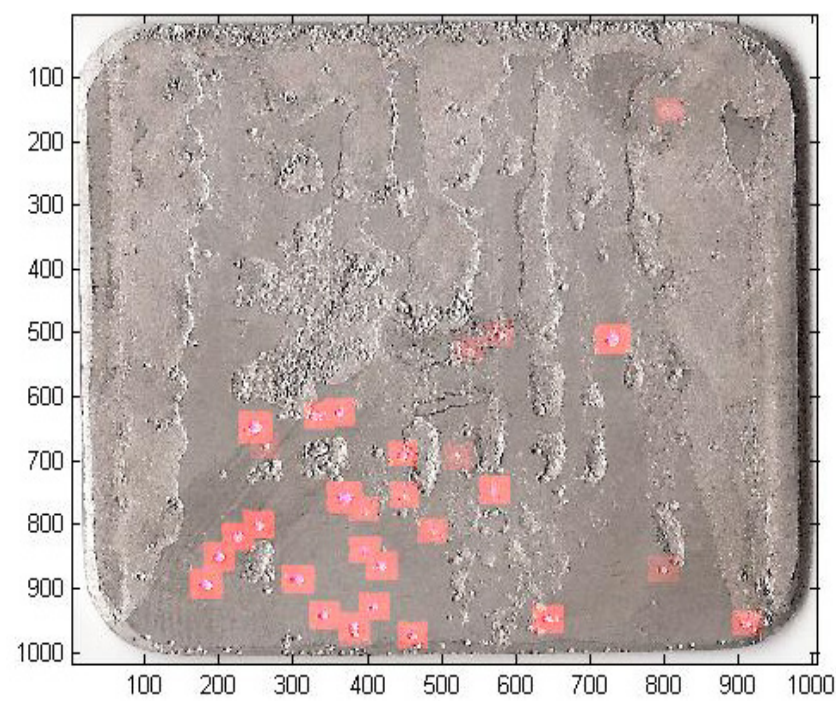

Figure 3. Corrosion coupon evaluation in Matlab - an example dotted corrosion evaluation

\subsection{Corrosion Rates Computation}

Corrosion rate $\mathrm{v}_{\mathrm{u}}\left(\mu \mathrm{m} \cdot \mathrm{r}^{-1}\right)$ is computed as follows (1):

$$
v_{u}=365 \frac{\left(U_{t 2}-U_{t 1}\right)}{t_{2}-t_{1}}
$$

where $t_{1}$ is shorter time of exposure (days), $t_{2}$ is longer time of exposure (days), $\mathrm{U}_{\mathrm{t} 1}$ is corrosion decay during shorter time of exposure $(\mu \mathrm{m})$ and $U_{t 2}$ is corrosion decay during longer time of exposure $(\mu \mathrm{m})$.

Corrosion decay $U_{t}(\mu \mathrm{m})$ is computed by the formula (2):

$$
U_{t}=\frac{1}{7.68}\left(k-k_{0}\right)
$$

where $U_{t}$ is corrosion decay during time of exposure $t, k$ is the mean value of corrosion decay from four coupons $\left(\mathrm{g} / \mathrm{m}^{2}\right), \mathrm{k}_{0}$ is corrosion decay of four coupons during the blank experiment $\left(\mathrm{g} / \mathrm{m}^{2}\right)$ and 7,68 is steel density $\left(\mathrm{g} / \mathrm{m}^{3}\right)$. Corrosion decay (3) of individual coupons $\mathrm{k}\left(\mathrm{g} / \mathrm{m}^{2}\right)$ :

$$
k=\frac{\left(m_{0}-m_{t}\right)}{S}
$$

where $m_{0}$ is weight of coupon before exposure $(\mathrm{g}), \mathrm{m}_{\mathrm{t}}$ is weight of coupon after exposure $(\mathrm{g}), \mathrm{S}$ is total surface of coupon before exposure $\left(\mathrm{m}^{2}\right)$.

Corrosion rates were computed according to the new method. The difference is in the fact, that they were computed for the corroded area of the coupon, not for the total area as it is done in the standard method. It should give us more accurate information about the stage of the corroded material.

\section{Results and Discussion}

\subsection{Coupon Tests Results}

The investigation was performed in the WTP Plav which provides potable water to many municipalities in South Bohemia. Three places were chosen as locations for corrosion monitoring and taken samples for the analysis of the main characteristics of the treated water from WTP Plav in South Bohemia.

Temperature, $\mathrm{pH}$, alkalinity levels, iron, manganese, calcium and magnesium concentration, disinfectant residual were measured at the inlet of WTP, in water after coagulation and filtration and at the outlet of WTP.

Corrosion rates were measured using removable steel coupons. The coupons were removed from the cradles after a 35 and 70 days incubation period. A comparison of corrosion coupons after exposition in raw water, filtered water and treated water are at Figure 4.

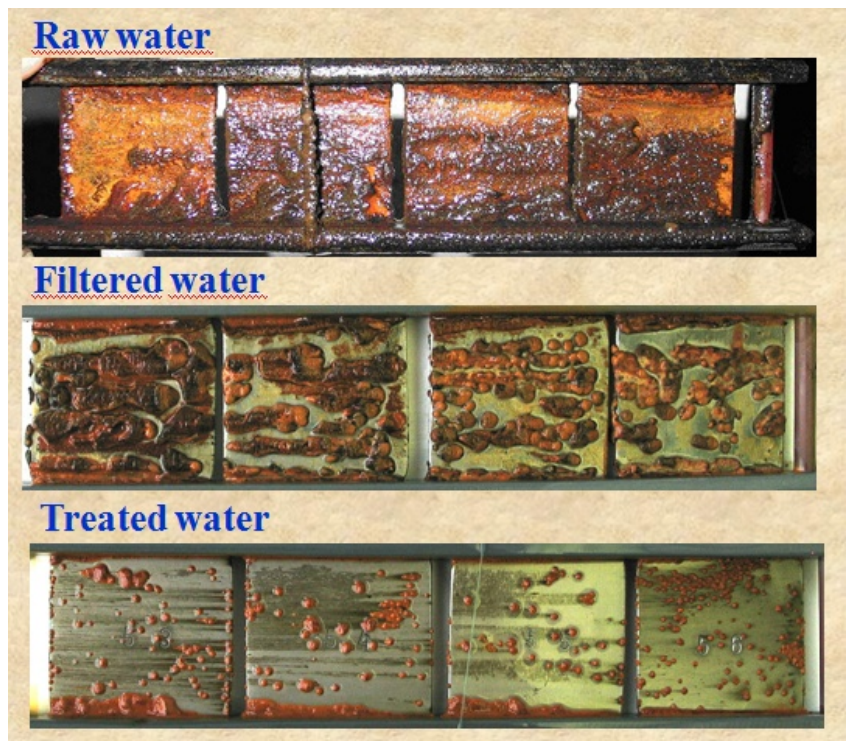

Figure 4. Coupons after exposure

After this 35 and 70 days period of exposition to water the coupons were analyzed using mass loss and a new scanner method as well. A software simulation study was carried out by using Matlab program and corrosion rates were computed for corroded areas of the coupons. 


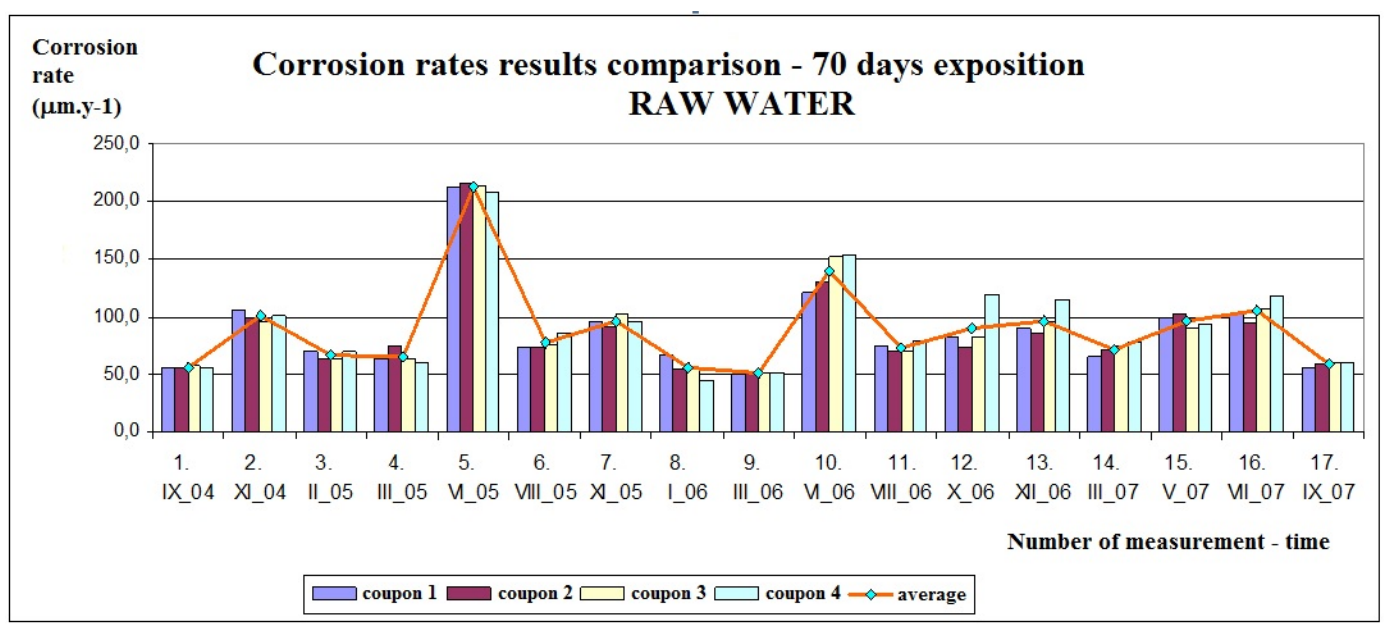

Figure 5. Corrosion rates results - raw water

Corrosion rate measured in crude water from Rímov reservoir after 35 resp. 70 days exposition was between 32,6 and 243,3 $\mu$ m.year ${ }^{-1}\left(\varnothing 83,1 \mu\right.$ m.year $\left.{ }^{-1}\right) \quad$ resp. 51 and 212,4 $\mu \mathrm{m}$.year ${ }^{-1}\left(\varnothing 89,0 \mu \mathrm{m}\right.$. year $\left.^{-1}\right)$ and in final drinking water after 35 resp. 70 days exposition was between 45,9 and $135,8 \mu \mathrm{m} . \operatorname{year}^{-1}\left(\varnothing 73,9 \mu \mathrm{m}\right.$. year $\left.^{-1}\right) \quad$ resp. 26,6 and 102,3 $\mu \mathrm{m}$.year ${ }^{-1}\left(\varnothing 51,3 \mu \mathrm{m}\right.$. year $\left.^{-1}\right)$. [6]

An example of corrosion rates evaluation and a comparison of four coupons for each measurement in raw water is at the Figure 5.

\section{Conclusion}

The goal of the work was to define the new method of corrosion coupon evaluation and differentiation between two types of corrosion: uniform and pitting corrosion.

Corrosion rates were computed according to the new method. The difference is in the fact, that they were computed for the corroded area of the coupon, not for the total area as it is done in the standard method. It should give us more accurate information about the stage of the corroded material.

Corrosion rate showed a typical seasonal pattern with the maximum values in the period from May to July and a minimum in winter.

\section{Acknowledgements}

This research was done in cooperation with JčVaK České Budějovice. It has been supported by NAZV grant $1 \mathrm{G} 46036$ and by SGS grant SGS 13/172/OHK1/3T/11.

\section{REFERNCES}

[1] R.E. Loewenthal, I. Morrison, M.C. Wentzel. Control of Corrosion and Agression in Drinking Water Systems, Water Science et Technology Vol.49, No.2, 9-18, 2004.

[2] C.Y. Peng, G.V. Korshin, R.L. Valentine, A.S. Hill, M.J. Friedman, S.H. Reiber. Characterization of elemental and structural composition of corrosion scales and deposits formed in drinking water distribution systems, Water Research 44 (15), 4570-4580, 2010.

[3] P.Sarin, V.L. Snoeyink, J. Bebee, W.M. Kriven, J.A. Clement. Physico-chemical characteristics of corrosion scales in old iron pipes. Water Research 35 (12), 2961-2969, 2001.

[4] Corrosion Types - Corrosion Forms, Online available from $\mathrm{http}: / /$ www.corrosionist.com/Corrosion_Types.htm

[5] M.M. Bishop, G. Iversen, P.C. Hazen and Sawyer, J. Scher, T. Broome. Johnston County, NC. Distribution System Corrosion - Solving Water Quality Problems Before or After the Fact Online available from http://www.ncsafewater.org/Pics/Training/AnnualConferenc e/AC07TechnicalPapers/CollectionDistribution/AC07CD_T ues0215_Bishop.pdf

[6] A. Grünwald, I. Čiháková, P. Fošumpaur, K. Slavíčková, M. Slavíček, B. Št’astný, B. Rohanová, K. Štrausová. Inovace procesu úpravy vody a zabezpečení vysoké kvality pitné vody v distribučních sítích" [Research report NAZV 1G46036]. Prague: CTU, Faculty of Civil Engineering, Department of Sanitary and Ecological Engineering, 2007, $102 \mathrm{p}$. 